\title{
Organizational Change Management: Delineating Employee Reaction to Change in SMEs Located in Magnesia
}

Dimitriadis Stavros

Corresponding author, BA, MSc in Management University of Staffordshire

Email: sdimi13@gmail.com

Blanas Nikolaos

Associate Professor, Department of Business Administration, T.E.I. of Thessaly

Email:nikoblan@teilar.gr

Aspridis George

Associate Professor, Department of Business Administration, T.E.I. of Thessaly

Email: aspridis@teilar.gr

Vetsikas Apostolos

Department of Planning and Regional Development, University of Thessaly Email: vetsikas@uth.gr

Doi:10.5901/ajis.2016.v5n1p309

\section{Abstract}

\begin{abstract}
Multidimensional and complex external environment of modern organizations require effective mapping of organizational change in their identity as only thus can achieve the long-term sustainability and gain a competitive advantage. However, this interface would not be possible without the valuable contribution of leaders and employees who play the most vital role in the implementation of change, serving as the most basic deterministic variable of success of new business strategies. Aim of this paper is the theoretical and empirical exploration of the concept and basic features of organizational change and its connection with issues of resistance to change on behalf of the employees. The results of a statistical study conducted with the use of a closed type questionnaire, answered by 120 employees in private SME's located in the area of Magnesia using methods of descriptive and inferential statistics, showed quite high openness to change and low degree of recognizing motives of resistance to change. Also, results showed that employees do not recognize important reasons for resistance to change while they are moderately satisfied with the applied strategies aiming on mitigation of resistance to change. These factors are correlated with each other and educational level influences employee reaction towards change, since less educated employees display stronger motives of resistance to change.
\end{abstract}

Keywords: Organizational change, employee resistance, change management, employee reaction, satisfaction

\section{Introduction}

Organizational change is the process of continuous renewal of organizations, along with redefining their strategic position and their capacity dynamic, in order to optimize their performance to an ideal situation, in response to developments in their internal and external environment. Organizational change can be the result of a great number of factors and conditions, which are associated with both the external and internal environment and, thus, has become an urgent requirement for most organizations currently due to several factors concerning the economy, technology and other political and social developments. In addition, the current volatile global economy, taking into account the recent financial crisis, and the emerging wave of mergers and acquisitions enforce new types of organizational change.

In addition, change management is essential for addressing employees' negative reactions to change, since any change, no matter how beneficial it can be for employees and the respective organization, it is expected that it will meet resistance. Indeed, employees tend to adapt to specific organizational circumstances, creating respective social relations 
and responding to changes that they consider that can disrupt their working environment. ${ }^{1}$

\section{Organizational Change, Change Management and Resistance to Change}

\subsection{Basic concepts and change types}

Change is an inevitable component for every individual and organization due to the need of adapting to the dynamic environment. The concept of change means the transition from one state to another, given a set of different conditions. This transition is a process of adaptation and repositioning of individuals or socially and economically organized groups of individuals in a new environment, where they are able to operate more effectively. Thus, according to Elliot (1990), change is a very complex psychological process, requiring special management and attention. In addition, change is a very usual condition for modern organizations, since technological revolution, increased competition, globalization and the turbulent business environment require consistent adaptation and transformation. Indeed, Allen (1978) reported that almost 30 years before, organizations should undertake a moderate organizational change at least once per year and one major change every four or five years. In contrast, today, the reality of organizational change is much different, as organizations constantly struggle with significant changes of the business environment.

\subsection{Reasons for change and change failures}

Organizational change can be the result of a great number of factors and conditions, which are associated with both the external and internal environment. Van de Ven et al (1995), trying to group the causes of organizational change, argued that this occurs under three conditions, technological change, dialectical change and due to the life cycle theoretical perspective. More specifically, in the first case, change is driven by technological evolution, the second type of change include the modification of the organizational vision, strategy, culture, structure, systems and production technology and in the third case, change is the result of the need of adjusting power structures of the internal environment (Yang et al 2009).

Moreover, Alas (2007) suggests that there are two basic forces of organizational change, the one that pushes the organization to a new direction and the other that prevents it from changes of the external environment. According to the behavioral theory of firm, the major driver of organizational change is performance, meaning that when performance decreases, the effectiveness of routines is called into question upon an environmental change and, thus, current business tactics are no longer aligned with the external environment (Wezel et al, 2005). As performance is considered as the most important signal of success or failure, any decline necessitates the adjustment and modification of the organization, leading to change when shareholders', customers', decisions makers' and employees' expectation are not met.

\subsection{Targets, stages and benefits of change}

As previously mentioned, organizational change can be evolutionary or revolutionary, depending on the forces and pressures imposing change. The vast majority of planned changes are undertaken to enable organizations to meet requirements and opportunities that have emerged in the external environment. Of course, there are cases where organizations have foreseen modifications of external forces, trying to adapt in the new situation successfully (Saka, 2003). In general terms, all attempted changes serves various purposes which could be grouped in the four following categories of business operations and activities (Gilgeous et al, 1999) : (a) commercial purposes, including all necessary actions in order to increase the market share, enter new markets, increase customer satisfaction, provide new products and services and, generally, gain a competitive advantage, (b) technological purposes, referring to actions for introducing and adopting new technology, including programs aiming to employees' familiarization with new technological inputs, (c) innovation purposes, encompassing actions and tactics for the production of new knowledge in the form of new products, services and organizational structures, which are not imposed exclusively by external pressures, such as compliance with legal requirements or achieving social acceptance, but mainly by an innovative organizational philosophy to pioneer, and (d) organizational purposes which refer to necessary actions in order to improve internal communication, efficient

${ }^{1}$ The article is a processed form of the dissertation submitted in partial fulfillment of the requirements of Staffordshire University for the award of MSc in Management. 
operation, individual productivity and organizational performance, including changes in leadership, programs of employees' motivation and talent management.

\subsection{Models of change management}

Blackman et al (2011) suggest that "sometimes, to change the people, you've got to change the people". Kotter (1996) remarks the last decades as a rapidly changing era where numerous challenges have been presented for organizations of all types, such as the scarcity of resources and the need to accomplish more with less, the increasing expectations of customers and stakeholders, changing regulatory environment, the evolution of Informational Technology Systems (ITS) and changing expectations of an increasingly diverse workforce. Blackman et al (2011) argue that the need for organizational change is widely accepted, however it is also a fact that this change is frequently unsuccessful, due to inappropriate change management.

According to Kotter (1995), organizations can follow an 8-step process to avoid failure, become adept by change and succeed in an ever- changing world. These steps are: (1) establish a sense of urgency, (2) create the guiding coalition, (3) develop a change vision, (4) communicate the vision for buy-in, (5) empower broad-based action, (6) generate short-term wins, (7) never let up, and (8) incorporate changes into the culture. In addition, Robertson (2008) suggests that the key elements in change management are : (a) create the case for change, (b) align, engage and mobilize leadership, (c) align, engage and mobilize organization and stakeholders, (d) establish the new organizational measurement system, (e) establish business processes and technology enablers, (f) manage the integrated program, and $(\mathrm{g})$ establish a capable organization.

\subsection{Change management strategies}

Strategic change management is the way of changing organizational objectives in order to gain greater success, although there is no generally accepted method of leading this success, taking into account that strategy formulation and execution is a difficult and complex task for every organization, having received great academic interest. When classifying organizational change strategies, almost all theoretical models of strategic change management are based on the threetype model of Chin et al (1969) regarding implementing change, namely rational empirical, power coercive and normative re-educative. In general terms, leadership is considered as one of the most fruitful strategy for change management, including managing control systems, using power tools and applying motivation and reward techniques.

\subsection{Resistance to change and culture change}

Although modern organizations face critical challenges imposed by the external environment and therefore the need of evolution is undeniable, in fact it is not quite clear how employees respond to changes (Briner et al, 2005). Any change, no matter how beneficial it can be for employees and the respective organization, it is expected that it will meet reactions (Del Val et al, 2003). Indeed, employees tend to adapt to specific organizational circumstances, creating respective social relations and responding to changes that they consider that can disrupt their working environment. So, one of the major reasons why the organizational change programs fail is the resistance exhibited by the employees due to their sense of being challenged by the changing status quo in their working environment (Ford et al 2008).

Therefore, resistance to change is considered as one of the most important concepts of modern organizations and is defined as a multidimensional phenomenon that slows down the process of organizational change, causing costs and instabilities as a result of employee efforts to maintain the current status quo (Kee et al, 2008). Resistance to change as a frequent organizational phenomenon is reflected in negative attitudes of staff towards strategic change initiatives (Coetzee et al, 2007) and is one of the most important factors of the possible failure of strategic change programs (Mdletye et al 2014). According to Lientz et al (2003), resistance to change can take two basic forms, namely: (1) active resistance, which can be attributed to culture and it can be seen when some employees openly question the changes and indicate a lack of support for change, and (2) passive resistance, which is difficult to detect, since employees may actually support for change, but when change is getting closer to being implemented, the resistance starts to come through.

There are several factors behind resistance to change, including management emphasizing cost savings over productivity and employees' satisfaction, poor training to address changes in the working environment, previous failures of change projects, fear of job cutbacks, fear of demotion or loss of position and different signals and messages sent by the change management team. Lientz et al (2003) suggest that all reasons behind resistance to change can be grouped 
in the following categories, lack of coordination and training in carrying out change for the change team, poor leadership by the change managers and lack of coordination among managers and between managers and the change team. In addition, Bovey et al (2001) argue that resistance to change is a process comprising four different stages, including initial denial, resistance, gradual exploration and final commitment, noting that resistance is a natural and normal response because change involves going from the known to the unknown. Researchers also emphasize that employees not only experience organizational change in different ways but they also differ in their ability and willingness to adapt to change (Bovey et al, 2001).

Furthermore, Wittig (2012) points out that is important to distinguish between the symptoms of employees' reactions to change and the causes behind them, noting that there are three important variables that strongly influence reaction, namely employees' emotions and cognitions, communication, and employees' participation in decision making. These factors, although they interrelate, explain much of employees' reactions during organizational change and, therefore, change management team should focus on them in order to address possible negative outcomes. In addition, Wittig (2012) argue that many change efforts fail since change agents underestimate the importance of the individual cognitive nature of change and the value of emotions expressed during all phases of organizational change.

Shin (2013) claims that employees who are dissatisfied with the way change is being implemented are more likely to suggest innovative ideas and solutions in order to improve the change process if they are more strongly committed to the purpose of the change and that they are less likely to exhibit promotive voice when they strongly believe that performance will deteriorate after the change is completed. Bruce et al (2011) argue that change without resistance is evidence that employees are not fully engaged or committed to current processes and systems and that widespread acceptance from the workforce towards fundamental business change is testament to the failings of the previous systems and organization.

Yang (2014) investigated how employees react to change and resistance by examining Employees at Volvo Cars. He argued that reactions to change and resistance exists in the people that are not engaged with the change and that communication plays an important role in how they react to change.

In sum, resistance to change is one of the most frequent employees' reactions to organizational change and it is considered as a normal and inevitable course of action due to fear of the unknown and uncertainty. In addition, resistance to change is the one of the leading causes of change initiatives' failure, since it has been recognized as an important factor that impacts the success of an organizational change effort. For this reason, it is essential for managers to identify the main reasons behind employees' resistance to change, outlining the benefits of change and implementing respective effective strategies for addressing it, in the frame of changing organizational culture.

\subsection{Addressing resistance to change}

Although resistance to change and possible employees' negative reactions to change initiatives may not be inevitable to some degree, various strategies can be implemented for addressing in before or when these negative behaviors and thoughts are manifested. Smollan (2011) proposes six different strategies, namely education and communication, participation and involvement, facilitation and support, negotiation and agreement, manipulation and cooptation, and coercion. All these strategies have their advantages and disadvantages and, thus, several situational factors should be taken into account by the change management team. Smollan (2011) also suggests that managers should reflect on the assessment of the potential impact of change on various stakeholders, including individuals, working groups and departments, the fact that resistance is an outcome of several cognitive, emotional and behavioral factors, handling resistance with care and underlining the positive outcomes of organizational change with honest communication.

According to Burns (2005), one of the major factors affecting effective treatment of resistance to change and, therefore, building an environment and an organizational culture characterized by a high degree of commitment on behalf of staff, is leadership, especially regarding senior management. Moreover, Vithessonhti (2007) points out the necessity of having a systematic plan change, in order to provide useful and integrated information for all employees involved in all change steps, methods and practices. In addition, Self et al (2007) report that for a change plan to be successful, it should be accounted for as a fair by employees, by incorporating appropriate strategies of minimizing the feeling of job unsafety and, accordingly, maximizing motivation for change.

Bovey et al (2001) come to similar conclusions, reporting that a key strategy of change management in order for organizational change to be accepted is addressing the defense mechanisms developed by the employees, in response to the stress resulting from the uncertain working environment. In this light, Elving (2005) points out that effective organizational communication reduces employees' feeling of uncertainty and, respectively, increases their willingness to 
accept change. Of course, the quantity and quality of information communicated to employees decisively influence the way in which they react to organizational change (Wanberg et al, 2000). One particular strategy that also affects in powerful way employees' reactions to change is to enhance the degree of their participation and involvement in decisionmaking processes (Bordia et al 2004).

The role of leadership during organizational change is also highlighted by Belias et al (2014), who suggest that strategic leadership needs to be transformational in order to serve organizational change and culture, since changing a culture is a large-scale undertaking. In this frame, leadership is associated with organizational culture, primarily through the process of articulating a vision and to a lesser extent through the setting of expectations (Belias et al 2015). In addition, Battistelli et al (2013) argue that leadership is important in change management and management of negative reactions to change due to its impact on job autonomy and feedback. More specifically, researchers investigated the views of 270 employees working in the public sector, in order to examine the moderating role of task autonomy and feedback from job in the relationship between dispositional resistance to change and innovative work behavior, proving that task autonomy significantly interact with both composite resistance to change and emotional reactions to change, as well as feedback from job has also an important role in managing reactions to change.

Accordingly, Mangundjayaa et al (2014) tried to identify the role of leadership and employee condition on reaction to organizational change, examining the perceptions of 539 employees working for state-owned organizations, and found that job satisfaction acts as mediator between change leadership and individual readiness for change and commitment to change, suggesting that leadership strategies are very important for organizational change management in order to plan and implement changes more effectively. Moreover, Shin et al (2012) argue that employees' commitment to change is positively linked to their behavioral support for change, which is enhanced by proper management strategies and refers to the extent to which employees demonstrate support and enthusiasm toward change by going along with the change spirit and going beyond their required roles and responsibilities to ensure the success of the change.

Katsaros et al (2014) explored employees' perceptions regarding organizational readiness to change, supervisory support, trust in management and appropriateness of change during a planned organizational change in a public hospital and found that if change initiatives are properly planned and the change vision is adequately shared, then readiness to change is increased, in line with trust in managers. In this study, it was also found that these aforementioned perceptions are moderated by certain job-related attitudes, namely, job satisfaction, organizational commitment and job involvement; and job-related characteristics, namely, skill variety, task identity, task significance feedback, autonomy and goal clarity. Predişcan et al (2013) claim that for successfully completing reducing resistance to change phase important resources such as necessary expertise in the field of change management, action coordination by competent change agents, time resources that will allow employees to accept the change as well as financial resources, necessary for motivating the affected by the change employees are needed.

\section{Research Methodology}

The population on whom the research was based is all SMEs employees of the Magnesia prefecture. This research was a descriptive one and with the use of quantitative data the authors tried to measure employee reaction towards change. For the purpose of this research 150 questionnaires were distributed and the study sample was amounted to 120 people.

To realize this project the authors set in advance a number of research questions and tasks that helped us analyze the issues of this study, based on literature review and on this thesis aims and objectives: What is the degree of openness of the employees to change?, What are the main motives of employee resistance to change and the degree that are experienced by them? What are the main reasons of employee resistance to change? Which are the opinions (satisfaction) of employees about strategies used to mitigate resistance to change and their perceived satisfaction by them? Define the relationship between the concepts that consist the resistance to change, what is the impact of employee demographic characteristics toward their reactions to change? Based on the above, the corresponding discrete research hypotheses of the research are:

- $\quad \mathrm{H} 1$ - There is a negative and statistically significant relationship between "openness to change" and "motives of resistance to change" factors.

- $\quad \mathrm{H} 2$ - There is a negative and statistically significant relationship between "openness to change" and "reasons for resistance to change" factors.

- H3 - There is a positive and statistically significant relationship between "openness to change" and "strategies to mitigate resistance to change" factors.

- H4 - There is a positive and statistically significant relationship between "reasons for resistance to change" 
and "motives of resistance to change" factors.

- $\quad \mathrm{H} 5$ - There is a negative and statistically significant relationship between "Strategies to mitigate resistance to change" and "motives of resistance to change" factors.

- $\quad \mathrm{H} 6$ - There is a negative and statistically significant relationship between "Strategies to mitigate resistance to change" and "reasons for resistance to change" factors.

- $\mathrm{H} 7$ - There is a statistically significant impact of demographic factors to "employees reactions to change" factors.

The statistical research was conducted based on a Likert - scale questionnaire which was created for the research and sent to local enterprises in Magnesia prefecture. The questionnaire was created in English language, translated in Greek and was based on literature review and similar past researches (Beer et al, Bratutanu, Mdletye, Song and others). Statements were divided into four categories/factors, "Openness to change", "Motives of resistance to change", "Reasons for resistance to change" and "Strategies to mitigate resistance to change". To test the internal consistency and reliability of the responses a-Cronbach's coefficient was calculated as it is shown at the following table. By testing the reliability coefficients of Cronbach for the individual factors of the questionnaire but also for the whole research tool, it was found that it is satisfactory in each case. Before distributing the questionnaire a pilot test was conducted and the responses of the research were processed with the statistical package SPSS 20.0.

Table 1: Cronbachs' Alpha

\begin{tabular}{|l|l|}
\hline Total questionnaire & $\mathbf{0 . 8 5 5}$ \\
\hline Openness to change & 0.909 \\
\hline Motives of resistance to change & 0.801 \\
\hline Reasons for resistance to change & 0.811 \\
\hline Strategies to mitigate resistance to change & 0.800 \\
\hline
\end{tabular}

\section{Results and Discussion}

According to research results, it was initially documented that employee openness to change is quite high, while the most significant motives of resistance to change are the feeling of insecurity, due to fear of losing their position and the sense of challenging their current status quo. Managers must be prepared to talk candidly about the needs for change, otherwise fear and uncertainty will remain a prevailing element that can damage morale and prevent successful implementation of the desired changes at all levels of the organization (Bateh et al, 2013). Indeed, it has been documented that employees tend to adapt to specific organizational circumstances and, thus, resistance is a normal reaction to change due to feelings of insecurity (Ford et al 2008; Mdletye et al 2014). In addition, it has been suggested that challenging the current status quo is one of the most basic motives behind employees' resistance to change (Kee et al, 2008; Coetzee et al, 2007).

Furthermore, statistical analysis showed that the main reasons for resistance to change is lack of rewards when change is successfully implemented and possible conflicts arising between employees and between employees and supervisors. On the other hand, the moderate degree of employees' resistance to change can be explained by the fact that they feel that they have the necessary information to accept organizational changes and they understand the change objectives. Effective communication and sharing of the change vision has been proved as a crucial factor of addressing resistance to change during change management (Smollan, 2011; Elving, 2005). In accordance, providing useful and integrated information for all employees involved in the change process is vital change management strategy (Vithessonhti, 2007; Wanberg et al, 2000).

Table 2: Mean scores of "Openness to change"

\begin{tabular}{|l|l|l|}
\hline \multicolumn{1}{|l|}{$\begin{array}{l}\text { When informed of significant change regarding the way things are done in my workplace, my initial reaction would be } \\
\text { to feel resistant. }\end{array}$} & 2.47 & 0.788 \\
\hline I am open to change in the workplace & 3.82 & 0.722 \\
\hline I accept changes in the workplace when introduced by the supervisor & 3.67 & 0.858 \\
\hline I resist change in the workplace & 2.11 & 0.828 \\
\hline Organizational change improves the quality of my work & 3.77 & 0.789 \\
\hline
\end{tabular}




\begin{tabular}{|c|c|}
\hline Organizational change improves productivity and efficiency in the workplace & \begin{tabular}{|l|l|l|l}
3.71 & 0.894 \\
\end{tabular} \\
\hline I trust supervisors when introducing changes in the workplace & \begin{tabular}{l|l}
3.28 & 0.802 \\
\end{tabular} \\
\hline I feel quite confident when changes are introduced & \begin{tabular}{|l|l|l|}
3.17 & 0.816 \\
\end{tabular} \\
\hline I trust my organization that will treat me fairly during changes & \begin{tabular}{l|l}
3.48 & 0.987 \\
\end{tabular} \\
\hline Openness to change & \begin{tabular}{|l|l|l|}
3.64 & 0.897 \\
\end{tabular} \\
\hline
\end{tabular}

This finding is further confirmed by research results concerning employees' views regarding strategies used in their companies to mitigate resistance to change. In particular, it was observed that employees think that ideas should be more openly communicated and discussed, that vision of change is effectively shared and that supervisors help encountering difficulties in the change process. On the other hand, the level of employees' satisfaction with the strategies applied is moderate, with the main problems focusing on poor planning and insufficient empowerment. In fact, poor planning is the leading cause of organizational change failures (Hughes, 2011), while it is a common place between researchers that employees' empowerment and enhancing their involvement in the decision-making processes during change is an effective change management strategy (Bordia et al 2004; Gray et al, 2002).

Regarding research's hypotheses, it is observed that $\mathrm{H} 1$ \& $\mathrm{H} 2$ are not accepted, as the correlation between "openness to change" and "reasons and motives of resistance to change" factors is negative but not statistically significant. Thus, our research's results showed that the level of openness to change is not determined by Motives and Reasons for resistance to change. This finding can be explained due to the fact that in this research, while employees showed a quite satisfactory degree of "openness to change" factor, the degrees of "Motives of resistance to change" and "Reasons for resistance to change" factors were low. As Bradutanu, (2012) argued, although the main motive why employees resist change is their personal interest, however most of them usually understand the need for change and believe that it will make sense for the organization. Conversely, $\mathrm{H} 3$ is accepted as it is observed that higher employee satisfaction regarding "strategies used to mitigate resistance to change" results higher "openness to change" degree in their working environment. Organizations that provide support to the employees help them encounter difficulties in the change process and understand why a change is happening and why it is necessary. Indeed, Bateh et al, (2013) state that to facilitate employee readiness and overcome resistance, some employees need to know that personnel are treated fairly during the process, while others are more concerned with the logic of the decision-making around the need for structural change. $\mathrm{H} 4$ of this research is also accepted as the correlation between "reasons for resistance to change" and "motives of resistance to change" factors is positive and statistically significant, proving an inextricable relationship between this two factors regarding employees reactions towards organizational change. Thus, with a logical approach, higher motives of employees lead to higher reasons for resistance to change. H5 \& H6 research hypothesis are also accepted as we observe that the correlation between "strategies to mitigate resistance to change" and "reasons for resistance to change" and "motives of resistance to change" factors is negative and statistically significant. Organizations who focus on their employees during change process, with management making higher efforts into change procedures in all levels, with better change readiness programs and training, have better chances that their employee's will show decreased motives and reasons to resist change in general. As Wittig (2012) argues employees' reactions to change are influenced by a number of factors, including employees' emotions and cognitions, communication, and participation in decision making. Finally, $\mathrm{H} 7$ of the study, suggests that there is statistically significant impact of the demographic factors to "employee's reactions to change" factors is partially confirmed as a relationship between the educational level and the "motives of resistance to change" factor is observed. Indeed, researchers have found that there is a significant and positive relationship between employees' educational level and readiness to change Al-Abrrow et al (2013).

Additionally, it was documented that there is a strong correlation between openness to change and employees' level of satisfaction with the change management strategies applied. Consequently, it can be clearly suggested that effective change strategies, including communication, sharing a common vision, empowerment and rewarding, are vital for enhancing the organizational level of readiness. Lastly, it was observed that none demographic factor influences employees' resistance to change, except from education, level since less educated employees showed stronger motives of resistance to change. Thus, it can be argued that change management should focus on less educated employees in order to mitigate negative attitudes towards organizational change, providing more training. To sum up, employees are quite open and adaptive to organizational change in SMEs located in the prefecture of Magnesia, although specific motives and reasons behind resistance to change require specific attention and strategies, including communication, clear planning, involvement, empowerment and training. 
Table 3: Resistance to change factors correlations

\begin{tabular}{|l|c|c|c|c|c|}
\hline & & $\begin{array}{c}\text { Openness to } \\
\text { change }\end{array}$ & $\begin{array}{c}\text { Motives of resistance } \\
\text { to change }\end{array}$ & $\begin{array}{c}\text { Reasons for resistance } \\
\text { to change }\end{array}$ & $\begin{array}{c}\text { Strategies to mitigate } \\
\text { resistance to change }\end{array}$ \\
\hline \multirow{2}{*}{ Openness to change } & rho & 1 & & & \\
\cline { 2 - 6 } & $p$ & - & & & \\
\hline \multirow{2}{*}{$\begin{array}{l}\text { Motives of resistance to } \\
\text { change }\end{array}$} & rho & -0.067 & 1 & & \\
\hline & $p$ & 0.484 & - & & \\
\hline $\begin{array}{l}\text { Reasons for resistance to } \\
\text { change }\end{array}$ & rho & -0.047 & 0.433 & & \\
\hline & $p$ & 0.625 & 0.000 & & \\
\hline $\begin{array}{l}\text { Strategies to mitigate } \\
\text { resistance to change }\end{array}$ & rho & 0.339 & -0.208 & -0.190 & \\
\cline { 2 - 6 } & $p$ & 0.000 & 0.026 & 0.042 & \\
\hline
\end{tabular}

\section{Conclusions}

Employees are quite open and adaptive to organizational change in SMEs located in the prefecture of Magnesia, although specific motives and reasons behind resistance to change require specific attention and strategies, including communication, clear planning, involvement, empowerment and training.

Modern organizations can remain competitive and achieve their long-term viability only when they have the capacity to support and implement effective continuous organizational change. However, despite the enormous importance attributed by the international research literature on the issue of efficient organizational change, this remains a goal that is especially difficult to achieve. This is because enterprises are living units that depend on the activity and influence a large number of variables and factors, which overlap and sometimes collide. Change management is part of the overall organizational strategy and refers to the management of those changes that must occur in response to changes that occur in the internal and external environment of organizations. However, the process of change is unique for each organization, although its effects are mostly long term and therefore should be managed in a unique way, as is commonly accepted that the circumstances and resources available in each case differ.

As in any research, this one also has some limitations. Further research should be conducted in a larger sample in order to generalize the results. Another limitation that should be considered is that this research was conducted during the Greek economic recession. Moreover, there were limitations regarding available budget and time. Finally, more parameters of the sample can be examined such as salary and job position in order to generalize or extract more specific results and conclusions.

\section{References}

Al-Abrrow, H.A., and Abrishamkar, M.M., (2013). Individual differences as a moderator of the effect of organizational commitment on readiness for change: a study of employees in the higher education sector in Iraq. International Journal of Management, 30(4), pp $294-301$.

Alas, R., (2007). Organizational Change from Learning Perspective. Problems and Perspectives in Management, $5(2)$, pp 43 - 50.

Allen, A., (1978). Organizational choice and general influence networks for diversified companies. Academy of Management Journal, 21 , pp $341-65$.

Bateh, J., Castaneda, M.E., and Farah, J.E., (2013). Employee resistance to organizational change. International Journal of Management \& Information Systems, 17(2), pp 113 - 16.

Battistelli, A., Montani, F., and Odoard, C., (2013). The impact of feedback from job and task autonomy in the relationship between dispositional resistance to change and innovative work behavior. European Journal of Work and Organizational Psychology, 22(1), pp $26-41$.

Beer, M. and Nohria, N., (2000). Cracking the Code of Change. Harvard Business Review.

Belias, D., and Koustelios, A., (2014). The impact of leadership and change management strategy on organizational culture. European Scientific Journal, 10(7), pp 451 - 70.

Belias, D., Koustelios, A., Vairaktarakis, G., and Sdrolias, L., (2015). Organizational Culture and Job Satisfaction of Greek Banking Institutions. Social and Behavioral Sciences, Vol 175. pp $314-23$.

Blackman, D., and Kennedy M., (2011). 'Sometimes, to Change the People, You've Got to Change the People' : When Learning is Not Enough. International Journal of Learning and Change, 3(4), pp 208 - 26.

Bovey, W., and Hede, A., (2001). Resistance to organizational change : The role of cognitive and affective processes. Journal of Managerial Psychology, 16(7), pp 534 - 48.

Bordia, P., Hobman, E., Jones, E., Gallois, C., and Callan, V., (2004). Uncertainty during organizational change: Types, consequences, and management strategies. Journal of Business and Psychology, 18(4), pp 507 - 32. 
Bradutanu, D., (2012). Do really employees resist change? Case study at a credit institution, Challenges of the Knowledge Society. Economics, pp $1263-268$.

Brinier, R.B. and Kiefer, T., (2005). Research into the Experience of Emotion at Work: Definitely Older, But are we any Wiser? In N.M. Ashkanasy, C. Hartel, \& W. Zerbe (Eds.), The effect of Affect in Organizational Settings - Research on Emotion in Organizations. Oxford, UK: Elsevier/JAI Press.

Bruce, J., Scott, P., and Roberts, M., (2011). Investigating employee resistance to Lean transformation : UK case study. UK Academy for Information Systems, in website http://eprints.port.ac.uk/2441/1/Bruce,_Scott_\%26_Roberts.v0.12.pdf, accessed on 12/10/2015.

Burnes, B., (2005). Complexity theories and organizational change. International Journal of Management Reviews, 7, pp 73 - 90.

Chin, R., and Benne, K., (1969). General Strategies for Effecting Change in Human Systems. In W. Bennis, K. Benne, \& R. Chin (eds.), The Planning of Change (32-59). New York: Holt, Rinehart \& Winston.

Coetzee, C.J.H., and Stanz, K.J., (2007). "Barriers-to-change" in a governmental service delivery type organization. SA Journal of Industrial Psychology, 33(2), pp 76 - 82.

Del Val, M.P., and Fuentes, C.M., (2003). Resistance to change : A literature review and empirical study. Management Decision, 41(2), pp 148 - 55.

Elliott, R.D., (1990). The challenge of Managing Change. Personal Journal, 69(3), pp 40 - 92.

Elving, W.J., (2005). The role of communication in organizational change. Corporate Communications, 10(2), pp 129 - 138.

Ford, J.D., Ford, L.W., and D'Amelio, A., (2008). Resistance to change: The rest of the story. The Academy of Management Review, 33(2), pp $362-77$.

Gilgeous, V., and Chambers, S., (1999). Initiatives for management resistance to change. Journal of General Management, 25(2), pp 44 $-58$.

Gray, J., and Laidlaw H., (2002). Part-time employment and communication satisfaction in an Australian retail organization. Employee Relations, 24(2), pp 211 - 28.

Hughes, M., (2011). Do 70 Per Cent of All Organizational Change Initiatives Really Fail? Journal of Change Management, 11(4), pp 451 $-64$.

Katsaros, K.K., Tsirikas, A.N., and Bani, S.M.N., (2014). Exploring employees' perceptions, job-related attitudes and characteristics during a planned organizational change. International Journal of Business Science and Applied Management, 9(1), pp 1 - 15.

Kee, J.E., and Newcomer, K.E., (2008). Why Do Change Efforts Fail. Public Manager, 37(3), pp 5 - 12.

Kotter, J., (1995). Leading Change: Why Transformation Efforts Fail. Harvard Business Review, 73, pp 58 - 67.

Kotter, J., (1996). Leading change. Boston: Harvard Business School Press.

Lientz, B., and Rea, C., (2003). Breakthrough IT Change Management. New York : Routledge.

Mangundjaya, W.L., Utoyo, D.B., and Wulandari, P., (2014). The Role of Leadership and Employee's Condition on Reaction to Organizational Change. Procedia - Social and Behavioral Sciences, 172, pp 471 - 78.

Mdletye, M.A., Coetzee, J., and Ukpere, W.I., (2014). The Reality of Resistance to Change Behaviour at the Department of Correctional Services of South Africa. Mediterranean Journal of Social Sciences, 5(3), pp 548 - 60.

Prediscan, M., Bradutanu, D., \& Roiban, R. N., (2013). Forces that enhance or reduce employee resistance to change. Annals of Faculty of Economics, 1(1), $1606-612$.

Saka, A., (2003). Internal change agents; view of the management of change problem. Journal of Organizational Change Management, 16(5), pp 450 - 96.

Shin, J., Taylor, M.S., and Seo, M., (2012). Resources for change: The relationships of organizational inducements and psychological resilience to employees' attitudes and behaviors toward organizational change. Academy of Management Journal, 55, pp 727 48.

Shin, J., (2013). Employee voice behavior during organizational change. PhD Dissertation, University of Maryland, College Park, USA.

Smollan, R., (2011). Engaging with Resistance to Change. University of Auckland Business Review, 13(1), pp 12 - 15.

Song, X., (2009). Why Do Change Management Strategies Fail? Illustrations with case studies. Journal of Cambridge Studies, 4(1), pp $6-15$.

Van de Ven, A.H., and Poole, M.S., (1995). Explaining development and change in organizations. Academy of Management Review, 20, pp $510-40$.

Vithessonthi, C., (2007). Perceptions affecting employee reactions to change: Evidence from privatization in Thailand. The Journal of American Academy of Business, 12(1), pp 248 - 55.

Wanberg, C.R., and Banas, J.T., (2000). Predictors and outcomes of openness to changes in a reorganizing workplace. The Journal of Applied Psychology, 85(1), pp 132 - 42.

Wezel, F.C., and Saka-Helmhout, A., (2005). Antecedents and Consequences of Organizational Change : 'Institutionalizing' the Behavioral Theory of the Firm. Organization Studies, 27(2), pp $265-86$.

Wittig, C., (2012). Employees' reactions to organizational change. Practitioner, 44(2), pp 23 - 38.

Yang, R.S., Zhuo, X.Z., and Yu, H.Y., (2009). Organization theory and management: cases, measurements, and industrial applications. Taipei : Yeh-Yeh.

Yang, X., (2014). Resistance to Organizational Change and the Value of Communication : the case of Volvo Cars Human Resources Department. Master Thesis in SHRM and Labour Relations, University of Gothenburg. 
